\title{
Hva betyr de enkelte dødsårsaksgrupper for utdanningsforskjellene i dødelighet?
}

\author{
Jon Ivar Elstad ${ }^{1}$, Dag Hofoss ${ }^{2}$ og Espen Dahl ${ }^{3}$ \\ ${ }^{1}$ NOVA og Institutt for sosiologi og samfunnsgeografi, Universitetet i Oslo \\ ${ }^{2}$ HØKH, Akershus universitetssykehus \\ ${ }^{3}$ Høgskolen i Oslo \\ Korrespondanse: Jon Ivar Elstad, NOVA, Pb 3223 Elisenberg, 0208 Oslo \\ Telefon: 22541288 E-post: Jon.I.Elstad@nova.no
}

\begin{abstract}
SAMMENDRAG
Artikkelen analyserer utdanningsforskjellene i dødelighet og undersøker hvilke dødsårsaksgrupper som særlig bidrar til de sosioøkonomiske helseforskjellene. Data kommer fra Statistisk sentralbyrås database FD-Trygd. Analyseutvalget består av praktisk talt alle bosatte i Norge i 1993 alder 25-66 år ( $\mathrm{N}=2,2$ millioner). Data har informasjon om utdanning og dødsfall/dødsårsaker 1994-2003 og ble analysert med logistisk regresjon (utfallsvariabel død/ikke-død 1994-2003 alle årsaker samlet og 18 dødsårsaksgrupper, aldersjustert). Beregninger av hvor mange dødsfall som kunne være unngått om dødsrisiko for alle hadde vært lik den faktiske risiko for høyere universitetsutdanning er foretatt. Analysene viste at oddsratioer (OR) for dødsfall, alle årsaker, økte systematisk med synkende utdanningsnivå. Utdanningsforskjellene var spesielt store for stoffmisbruksrelaterte dødsfall og over gjennomsnittet for alkoholrelaterte dødsfall, lungekreft, kroniske lungelidelser. Variasjonene med utdanning var også særlig store for ischemisk hjertesykdom blant kvinnene. De fleste kreftformene unntatt lungekreft viste forholdsvis små utdanningsforskjeller. Blant kvinnene var det ingen utdanningsulikhet for tykk/endetarmskreft, brystkreft, selvmord og trafikkulykker. Om dødsrisikoen i alle utdanningsgrupper hadde vært lik risikoen blant dem med høyere universitetsutdanning ville 43000 av de 104000 dødsfallene som faktisk fant sted 1994-2003 vært unngått. Dødsfall i hjerte- og karlidelser, lungekreft og kronisk lungesykdom sto for nær $60 \%$ av de "ekstra" dødsfallene for begge kjønn. Store helsegevinster vil oppnås om utdanningsforskjellene i dødelighet reduseres. En minsking av ulikhetene i dødelighet i hjerte- og karlidelser, lungekreft og kronisk lungesykdom ville ha særlig betydning for å redusere de samlete utdanningsforskjellene i dødelighet.
\end{abstract}

\section{Elstad JI, Hofoss D, Dahl E. Contribution of specific causes of death to educational differences in mortality. Nor J Epidemiol 2007; 17 (1): 37-42.}

\section{ENGLISH SUMMARY}

This article analyses educational inequalities in mortality and examines the role of different causes of death for these differences. Data are constructed by linkages of Norwegian administrative registers. The analysed sample consists of practically all men and women living in Norway in 1993 and aged 25-66 years $(\mathrm{N}=2.2$ millions). Deaths 1994-2003, classified into 18 groups of causes, were analysed by age-adjusted logistic regression (outcome variable died/survived 1994-2003). Age-adjusted estimations of how many deaths could potentially be avoided if mortality risk for all educational levels had been equal to the risk among higher university educated (12\% of the sample) were made. During 1994-2003, 104,000 of the sample died (men $5.8 \%$, women 3.5\%). Odds ratios (ORs) for all deaths increased for each descending level of education (ORs basic education versus higher university 2.6/2.2 for men/women). Educational differences were very large for substance abuse deaths and well above average for chronic lung disease and alcohol-related deaths. ORs were also clearly above average for lung cancer deaths (both sexes) and ischaemic heart disease deaths (only women). Educational differences were relatively small or insignificant for other cancer categories. Among women, no educational inequalities were found for colorectal cancer, suicide, breast cancer, and traffic accidents. If death risk in lower educational levels had been equal to the observed death risk in higher university education, $43 \%$ (men) and 39\% (women) of the actually occurring deaths 19942003 would have been avoided. More than half of these potentially avoided deaths occurred among those with basic education (25\% of the sample). Cardiovascular diseases represented $38 \%$ (men) and $35 \%$ (women) of this hypothetical potential for avoided deaths. Also lung cancer ( $12 \%$ both sexes) and chronic lung disease $(6 \%$ men, $11 \%$ women) contributed strongly to the number of excess deaths. Findings are interesting in view of current discussions about strategies for reducing socioeconomic inequalities in health. 


\section{Problemstilling}

Strategier for å redusere sosiale helseulikheter blir drøftet $\mathrm{i}$ en rekke europeiske land (1-5). Bedre kunnskap om betydningen av de enkelte dødsårsaksgruppene for disse ulikhetene kan være nyttig for denne debatten. I denne artikkelen analyserer vi hvordan voksnes dødelighet i Norge varierer med utdanningsnivå, for alle dødsårsaker samlet og for spesifikke dødsårsaksgrupper. Siktemålet er å kartlegge hvilke dødsårsaker som varierer særlig sterkt og hvilke som i liten grad varierer mellom utdanningsnivåene. Et videre siktemål er å anslå hvor mye hver av dødsårsaksgruppene bidrar til den samlete utdanningsulikheten i dødelighet. Svarene på de to spørsmålene faller ikke sammen. Selv om en dødsårsak varierer sterkt med utdanning, kan bidraget den gir til de sosiale forskjellene i dødelighet være ubetydelig dersom dødsårsaken ikke forekommer ofte.

\section{DATA OG METODE}

Data kommer fra Statistisk sentralbyrås database FDTrygd (6). Utvalget består av alle menn og kvinner født 1927-1968 som var registrert bosatt i Norge i 1993 og i live ved utgangen av dette året. Til materialet er det koblet opplysninger om høyeste oppnådde utdanning i 1992 fra Statistisk sentralbyrås utdanningsregister og informasjon om dødsfall 1994-2003 fra dødsårsaksregisteret. Vel 2,2 millioner personer i aldersgruppen 25-66 år i 1993 (1 115975 menn og 1089285 kvinner) blir analysert her.

Utdanning ble klassifisert i fem nivåer: Høyere universitetsutdanning, dvs. minst cand.mag.-nivå eller tilsvarende (11,7\% av analyseutvalget), lavere universitetsutdanning eller høyskole $(10,5 \%)$, videregående skole nivå II, høy (26,0\%), videregående nivå I, lavere $(26,8 \%)$ og grunnskolenivå $(25,1 \%)$. Dødsårsakene ble kodet $\mathrm{i}$ tråd med International Classification of Disease (ICD). ICD 9. revisjon er brukt for dødsfall 1994-1995 og 10. revisjon for seinere dødsfall (7). Dødsårsakene ble klassifisert i 18 grupper samt en restgruppe. Alder er brukt som kontrollvariabel og klassifisert i sju grupper (25-30 år i 1993, 31-36 år, osv. til 61-66 år).

Utdanningsvariasjonene for dødsfall i alt og dødsfall for hver av de 18 dødsårsaksgruppene 1994-2003 ble analysert ved hjelp av logistisk regresjon. Utfallsvariabelen var død/ikke-død i tiårsperioden. Analysene er gjort separat for hvert kjønn. Vi rapporterer oddsratio (OR) for hvert utdanningsnivå (referansekategori høyere universitetsutdanning) og oddsratioenes 95\% konfidensintervall. Analysene er justert for alder (sju aldersgrupper inkludert som kategorisk variabel).

Videre har vi beregnet hvor mange "ekstra" dødsfall utdanningsulikhetene i dødelighet medførte i observasjonsperioden. Dette ble gjort ved å estimere hvor mange dødsfall som ville ha funnet sted i hver av de fire lavere utdanningsgruppene dersom prosentandelen som døde 1994-2003 hadde vært den samme som i den høyeste utdanningsgruppen. Beregningene ble gjort for hvert kjønn og basert på utregninger for hver enkelt av de sju alderskategoriene. Differensen mellom antallet faktisk døde 1994-2003 og beregnet antall døde gitt disse forutsetningene er et uttrykk for hvor mange dødsfall som kunne unngås $i$ fall en kunne redusere dødeligheten blant de lavere utdanningsgruppene til nivået blant de best utdannete.

\section{RESUlTATER}

Samlet antall dødsfall 1994-2003 i analyseutvalget var 103 746, fordelt på 65137 blant mennene og 38609 blant kvinnene (tabell 1). I analyseutvalget døde 5,8\% av mennene og $3,5 \%$ av kvinnene i løpet av tiårsperioden. Dødsfall i hjerte- og karsykdommer utgjorde $33,3 \%$ av alle dødsfall blant mennene, men en mindre andel $(21,6 \%)$ av dødsfallene blant kvinnene. Kreftdødsfallene sto for $33,1 \%$ av dødsfallene blant menn, men for hele $49,5 \%$ av dødsfallene blant kvinnene.

Utdanningsforskjellene i dødelighet for alle dødsfall og for de enkelte dødsårsaksgruppene er vist $i$ tabell 2 (menn) og tabell 3 (kvinner). For dødsfall, alle årsaker, steg oddsratioene (OR) for begge kjønn systematisk og forholdsvis regelmessig for hvert steg nedover i utdanningshierarkiet. Utslagene var sterkere for menn enn for kvinner: OR for grunnskoleutdannete var henholdsvis 2,63 og 2,21.

Tabell 2 viser at det var utdanningsvariasjoner for alle de 17 dødsårsaksgruppene blant mennene. Med noen unntak (infeksjonssykdommer, noen av kreftkategoriene, symptomer/ubestemte årsaker) var mønsteret systematisk i den forstand at OR økte, trinn for trinn, for hvert steg nedover på utdanningsskalaen. Selv høyt i utdanningshierarkiet fantes dette mønsteret: OR for lavere universitetsutdanning var høyere enn for høyere universitetsutdanning for 11 av de 17 dødsårsaksgruppene analysert blant mennene (dvs. nedre verdi for konfidensintervallet var over 1,00).

Helningen på utdanningsgradienten varierte imidlertid. Ytterpunktet var dødsfall relatert til stoffavhengighet o.1., der OR for menn med grunnskole var hele 45,6. Videre steg OR for dødsfall i kroniske lungesykdommer/KOLS og for alkoholmisbruksrelaterte dødsfall svært sterkt og regelmessig med synkende utdanning. Også for leversykdommer og lungekreft var utdanningsvariasjonene spesielt markante. På den annen side var utdanningsvariasjonene nesten fraværende for kreft i tykktarm/endetarm. Selv om det typiske mønsteret også gjaldt samlekategorien annen kreft, var økningen av OR med synkende utdanning forholdsvis liten for denne dødsårsaksgruppen.

Blant kvinnene (tabell 3) var det noen likheter med mønsteret blant mennene, men også klare forskjeller. Også blant kvinnene var utdanningsvariasjonene ekstreme for dødsfall knyttet til stoffavhengighet, svært store for kronisk lungesykdom/KOLS, og markant over gjennomsnittet for leversykdommer, alkoholmisbruksrelaterte dødsfall og (litt svakere) for lungekreft. 
Tabell 1. Deskriptiv statistikk. Klassifisering av dødsårsaksgrupper i henhold til International Classification of Disease (ICD), 9. og 10. revisjon. Antall dødsfall i alt 1994-2003 og antall dødsfall i spesifikke dødsårsaksgrupper. Menn og kvinner, 25-66 år i 1993 ( N=2 205 260).

\begin{tabular}{lrr}
\hline & \multicolumn{2}{c}{ Antall dødsfall } \\
\cline { 2 - 3 } Dødsårsak (ICD10-koder; ICD9-koder) & Menn & Kvinner \\
\hline Alle årsaker (A00-Y89; 001-E99) & 65137 & 38609 \\
Infeksjonssykdommer (A00-B99; 001-139) & 725 & 409 \\
Magekreft (C16; 151) & 1158 & 595 \\
Kreft i tykktarm, endetarm (C18-C21; 153-154) & 2836 & 2359 \\
Lungkreft (C34; 162) & 5814 & 3451 \\
Brystkreft (C50; 174-175) & 11732 & 3649 \\
Annen kreft (Andre C; 140-208) & 1347 & 9054 \\
Alkoholbetingete psykoser/alkoholavhengighet (F10; 291, 303) & 1127 & 265 \\
Avhengighet av stoff, medikamenter (F11-F19; 304-305) & 13709 & 4082 \\
Ischemisk hjertesykdom (I20-I25; 410-414) & 3291 & 2202 \\
Karsykdommer i hjernen (I60-I69; 430-438) & 4676 & 2074 \\
Annen sykdom i sirkulasjonsorganer (Andre I; 390-459) & 2116 & 1889 \\
Kronisk sykdom nedre luftveier (KOLS) (J40-J47; 490-494) & 967 & 583 \\
Annen sykdom åndedrettsorganene (Andre J; 460-519) & 1161 & 576 \\
Leversykdom (K70-K77; 571) & 2799 & 984 \\
Symptomer og ubestemte tilstander (R00-R99; 780-799) & 1342 & 384 \\
Transportulykker (V01-V99 Y85; E800-E848) & 2360 & 729 \\
Alle andre ulykker (W00-X59 Y86; E850-E929) & 2367 & 925 \\
Selvmord (X60-X84 Y87.0; E950-E959) & 5610 & 4146 \\
Andre dødsårsaker (andre A00-Y89; andre 001-E99) & &
\end{tabular}

Det spesielle blant kvinnene var imidlertid at også ischemisk hjertesykdom framviste en særskilt sterk utdanningsgradient, klart brattere enn for kvinners dødsfall i alt. Utpregete utdanningsforskjeller var også til stede for karsykdommer i hjernen og annen åndedrettssykdom. På den annen side var det ingen signifikant sammenheng mellom utdanningsnivå og dødelighet blant kvinnene for kreft i tykktarm/endetarm, brystkreft, transportulykker og selvmord. For magekreft var det bare de grunnskoleutdannete som hadde noe høyere dødelighet enn de andre.

Tabell 4 viser resultatet av beregningene av hvor mange dødsfall som kunne vært unngått 1994-2003 om prosentandelen døde innen hver utdanningsgruppe hadde vært den samme som blant dem med høyere universitetsutdanning. Samlet antall dødsfall blant mennene ville gått ned fra 65137 til 37 106, og blant kvinnene fra 38609 til 23 508. Potensialet for sparte dødsfall, gitt slike forutsetninger, utgjorde altså omlag $43 \%$ av de observerte dødsfallene blant mennene 1994-2003. Tilsvarende kunne omlag 39\% av dødsfallene blant kvinnene vært unngått. Av denne hypotetiske mengden av innsparte dødsfall blant menn ville vel halvparten $(15308$ av $28031=54 \%)$ ha skjedd blant dem med grunnskoleutdanning, mens tilsvarende tall for kvinnene var 64\%. Av det samlete tallet "ekstra" dødsfall, begge kjønn samlet, som vi her tilskriver utdanningsforskjellene, sto de med grunnskoleutdanning for omlag $58 \%$.

I tabell 5 er de "ekstra" dødsfallene fordelt på årsaksgrupper. Ischemisk hjertesykdom sto for vel $25 \%$ av de "ekstra" dødsfallene blant menn og for nær $20 \%$ blant kvinner. Tilsvarende tall for alle de tre gruppene av hjerte- og karsykdommer samlet var 38\% blant mennene og 35\% blant kvinnene. Lungekreftdødsfall sto for $12,5 \%$ av de "ekstra" dødsfallene for begge kjønn. Videre utgjorde kroniske lungesykdommer/ KOLS 5,9\% av de "ekstra" dødsfallene blant menn og $10,8 \%$ av de "ekstra" dødsfallene blant kvinnene.

Dødsårsakene som en antar ofte kan tilskrives misbruk (stoffavhengighet, høyt alkoholinntak, leversykdom) hadde en særskilt sterk utdanningsgradient, men deres bidrag til det samlete antallet "ekstra" dødsfall var relativt beskjedent. Samlet står disse tre årsaksgruppene for $9,5 \%$ av de "ekstra" dødsfallene blant menn og 5,3\% blant kvinnene. Når det gjelder ende/tykktarmskreft, brystkreft, transportulykker og selvmord blant kvinnene ville antallet dødsfall faktisk ha økt litt om dødeligheten blant alle kvinner hadde vært lik dødeligheten blant de best utdannete.

\section{DISKUSJON}

\section{Datamateriale og metoder}

Analyseresultatene er trolig svært dekkende for den faktiske situasjonen i Norge rundt årtusenskiftet. Datamaterialet omfatter praktisk talt hele populasjonen i Norge i 1993. Utdanningsopplysninger manglet for bare $0,2 \%$. Underliggende dødsårsak var oppgitt for praktisk talt alle de registrerte dødsfallene. Målefeil kan ha oppstått om utdanningsopplysningene var ufull- 
Tabell 2. Menn, alder 25-66 år i 1993. Logistiske regresjonsanalyser av utdanningseffekt på død/ikke-død 1994-2003, alle dødsårsaker samlet og 17 dødsårsaksgrupper. Odds ratioer (OR) og 95\% konfidensintervall (95\% KI). Aldersjustert.

\begin{tabular}{lccccccccc}
\hline & Høy universitet & \multicolumn{2}{c}{ Lavere } & universitet & \multicolumn{2}{c}{ Videregående II } & \multicolumn{2}{c}{ Videregående I } & \multicolumn{2}{c}{ Grunnskole } \\
& Ref & OR & $95 \% \mathrm{KI}$ & OR & $95 \%$ KI & OR & $95 \%$ KI & OR & $95 \%$ KI \\
\hline Alle dødsfall 1994-2003 & 1 & 1,36 & $1,30-1,42$ & 1,61 & $1,56-1,67$ & 2,03 & $1,96-2,11$ & 2,63 & $2,54-2,72$ \\
Infeksjonssykdommer & 1 & 1,00 & $0,68-1,46$ & 0,96 & $0,71-1,31$ & 1,49 & $1,10-2,01$ & 2,40 & $1,81-3,18$ \\
Magekreft & 1 & 1,51 & $1,11-2,04$ & 1,52 & $1,17-1,96$ & 1,61 & $1,24-2,10$ & 2,21 & $1,73-2,83$ \\
Kreft tykk/endetarm & 1 & 1,18 & $0,99-1,40$ & 1,21 & $1,05-1,40$ & 1,13 & $0,98-1,31$ & 1,26 & $1,09-1,44$ \\
Lungekreft & 1 & 2,08 & $1,76-2,45$ & 2,45 & $2,12-2,83$ & 2,80 & $2,43-3,24$ & 4,09 & $3,57-4,70$ \\
Annen kreft & 1 & 1,08 & $0,99-1,19$ & 1,24 & $1,16-1,34$ & 1,28 & $1,19-1,38$ & 1,44 & $1,35-1,55$ \\
Alkoholrel. psykoser mv. & 1 & 1,56 & $1,09-2,23$ & 2,13 & $1,58-2,86$ & 3,46 & $2,58-4,63$ & 5,82 & $4,40-7,71$ \\
Stoffavhengighet mv. & 1 & 3,70 & $1,74-7,83$ & 6,14 & $3,14-12,0$ & 26,93 & $13,9-52,2$ & 45,58 & $23,6-88,1$ \\
Ischemisk hjertesykdom & 1 & 1,60 & $1,44-1,77$ & 1,95 & $1,78-2,12$ & 2,37 & $2,18-2,59$ & 3,22 & $2,97-3,50$ \\
Karsykdommer hjernen & 1 & 1,22 & $1,00-1,49$ & 1,53 & $1,31-1,80$ & 1,94 & $1,66-2,28$ & 2,39 & $2,05-2,78$ \\
Andre sirkulasjonsorganer & 1 & 1,52 & $1,29-1,80$ & 1,73 & $1,50-2,00$ & 2,11 & $1,83-2,43$ & 2,86 & $4,93-3,27$ \\
Kronisk lungesykdom & 1 & 2,78 & $1,93-4,01$ & 4,18 & $3,01-5,78$ & 5,44 & $3,93-7,52$ & 7,65 & $5,57-10,49$ \\
Annen åndedrettssykdom & 1 & 1,21 & $0,82-1,80$ & 1,57 & $1,14-2,16$ & 1,95 & $1,42-2,68$ & 3,04 & $2,26-4,10$ \\
Leversykdommer & 1 & 1,64 & $1,14-2,35$ & 2,40 & $1,78-3,23$ & 3,59 & $2,68-4,82$ & 4,08 & $3,06-5,44$ \\
Symptomer, ubestemt & 1 & 1,64 & $1,35-1,99$ & 1,55 & $1,31-1,83$ & 1,87 & $1,57-2,21$ & 2,64 & $2,25-3,11$ \\
Transportulykker & 1 & 1,40 & $1,05-1,86$ & 1,65 & $1,31-2,09$ & 2,26 & $1,78-2,86$ & 2,73 & $2,17-3,44$ \\
Andre ulykker & 1 & 1,11 & $0,88-1,41$ & 1,69 & $1,40-2,03$ & 2,43 & $2,02-2,91$ & 3,14 & $2,63-3,75$ \\
Selvmord & 1 & 1,08 & $0,88-1,32$ & 1,32 & $1,13-1,55$ & 1,92 & $1,63-2,25$ & 2,15 & $1,83-2,52$ \\
\hline
\end{tabular}

Tabell 3. Kvinner, alder 25-66 år i 1993. Logistiske regresjonsanalyser av effekt av utdanning for død/ikke-død 1994-2003, alle dødsårsaker samlet og 18 dødsårsaksgrupper. Odds ratioer (OR) og 95\% konfidensintervall (95\% KI). Aldersjustert.

\begin{tabular}{lccccccccc}
\hline & Høy universitet & \multicolumn{2}{c}{ Lavere universitet } & \multicolumn{2}{c}{ Videregående II } & \multicolumn{2}{c}{ Videregående I } & \multicolumn{2}{c}{ Grunnskole } \\
& Ref & OR & $95 \%$ KI & OR & $95 \%$ KI & OR & $95 \%$ KI & OR & $95 \%$ KI \\
\hline Alle dødsfall 1994-2003 & 1 & 1,17 & $1,10-1,25$ & 1,40 & $1,32-1,49$ & 1,57 & $1,48-1,66$ & 2,21 & $2,09-2,33$ \\
Infeksjonssykdommer & 1 & 0,93 & $0,47-1,87$ & 1,24 & $0,67-2,28$ & 1,70 & $0,99-2,93$ & 3,12 & $1,83-5,33$ \\
Magekreft & 1 & 0,92 & $0,57-1,48$ & 0,98 & $0,63-1,54$ & 1,07 & $0,73-1,58$ & 1,54 & $1,05-2,25$ \\
Kreft tykk/endetarm & 1 & 0,86 & $0,68-1,07$ & 1,09 & $0,88-1,35$ & 1,06 & $0,88-1,27$ & 1,11 & $0,93-1,34$ \\
Lungekreft & 1 & 1,17 & $0,89-1,52$ & 1,83 & $1,44-2,33$ & 2,12 & $1,70-2,63$ & 3,58 & $2,89-4,44$ \\
Brystkreft & 1 & 1,03 & $0,88-1,20$ & 1,04 & $0,90-1,20$ & 0,93 & $0,82-1,06$ & 0,93 & $0,82-1,06$ \\
Annen kreft & 1 & 1,23 & $1,09-1,38$ & 1,26 & $1,12-1,41$ & 1,38 & $1,24-1,53$ & 1,68 & $1,51-1,86$ \\
Alkoholrel. psykoser mv. & 1 & 0,97 & $0,35-2,67$ & 3.01 & $1,32-6,84$ & 2,79 & $1,29-6,05$ & 4,92 & $2,29-10,59$ \\
Stoffavhengighet mv. & 1 & 2,91 & $0,75-11,25$ & 4,37 & $1,33-14,36$ & 16,34 & $5,17-51,66$ & 40,58 & $12,89-128$ \\
Ischemisk hjertesykdom & 1 & 2,09 & $1,51-2,90$ & 3,00 & $2,20-4,10$ & 3,67 & $2,74-4,92$ & 6,29 & $4,70-8,41$ \\
Karsykdommer hjernen & 1 & 1,61 & $1,14-2,29$ & 2,49 & $1,80-3,44$ & 2,59 & $1,91-3,50$ & 3,66 & $2,71-4,95$ \\
Andre sirkulasjonsorganer & 1 & 1,22 & $0,85-1,74$ & 1,64 & $1,18-2,30$ & 1,98 & $1,46-2,68$ & 3,12 & $2,31-4,20$ \\
Kronisk lungesykdom & 1 & 2,50 & $1,36-4,59$ & 4,61 & $2,59-8,21$ & 5,62 & $3,24-9,75$ & 11,32 & $6,55-19,60$ \\
Annen åndedrettssykdom & 1 & 1,39 & $0,68-2,85$ & 1,69 & $0,86-3,34$ & 2,48 & $1,34-4,58$ & 4,13 & $2,25-7,59$ \\
Leversykdommer & 1 & 2,14 & $1,07-4,31$ & 4,15 & $2,20-7,84$ & 3,78 & $2,05-6,95$ & 6,30 & $3,44-11,56$ \\
Symptomer, ubestemt & 1 & 1,22 & $0,82-1,82$ & 1,59 & $1,10-2,30$ & 1,40 & $1,00-1,96$ & 2,15 & $1,54-3,00$ \\
Transportulykker & 1 & 0,93 & $0,59-1,47$ & 0,86 & $0,58-1,29$ & 1,01 & $0,71-1,46$ & 1,06 & $0,73-1,54$ \\
Andre ulykker & 1 & 0,82 & $0,51-1,32$ & 1,47 & $0,99-2,17$ & 1,62 & $1,13-2,32$ & 2,76 & $1,93-3,94$ \\
Selvmord & 1 & 1,08 & $0,82-1,43$ & 0,89 & $0,69-1,15$ & 1,10 & $0,88-1,39$ & 1,11 & $0,87-1,41$ \\
\hline
\end{tabular}

stendige, eller ved at emigrasjon har ført til at dødsfall ikke er blitt registrert. Registrering av dødsårsaker er vanskelig og kan utgjøre en feilkilde (7), men det er lite trolig at feil her kan ha hatt stor betydning for hvordan utdanningsforskjellene framtrer $i$ analyseresultatene.

\section{Hovedresultater og kommentarer}

Analysene viser, i tråd med tidligere studier $(8,9)$, de omfattende og systematiske utdanningsforskjellene i dødelighet i Norge rundt årtusenskiftet. Utdanningsgradienten for dødsfall, alle årsaker samlet, var mar- 
Tabell 4. Observerte dødsfall 1994-2003 i fem utdanningsnivåer og beregnet antall dødsfall om prosentandelen døde i hver utdanningskategori var lik prosentandelen døde blant dem med høyere universitetsutdanning. Menn og kvinner, alder 25-66 år i 1993.*

\begin{tabular}{lccrrrr}
\hline & $\begin{array}{c}\text { Høyere } \\
\text { universitet }\end{array}$ & $\begin{array}{c}\text { Lavere } \\
\text { universitet }\end{array}$ & $\begin{array}{c}\text { Videre- } \\
\text { gående II }\end{array}$ & $\begin{array}{c}\text { Videre- } \\
\text { gående I }\end{array}$ & Grunnskole & Ialt \\
\hline Menn & & & & & & \\
Faktisk antall døde & 3804 & 4520 & 14439 & 14199 & 28175 & 65137 \\
Beregnet antall døde* & 3804 & 3446 & 9320 & 7669 & 12867 & 37106 \\
Differanse & 0 & 1074 & 5119 & 6530 & 15308 & 28031 \\
Kvinner & & & & & & \\
Faktisk antall døde & 1506 & 2364 & 3557 & 12273 & 18909 & 38609 \\
Beregnet antall døde* & 1506 & 2048 & 2528 & 8164 & 9262 & 23508 \\
Differanse & 0 & 316 & 1029 & 4109 & 9647 & 15101 \\
\hline
\end{tabular}

* Basert på spesifikke beregninger i sju alderskategorier.

Tabell 5. Fordeling av antall dødsfall som ville vært unngått om prosentandel døde 1994-2003 i alle utdanningskategorier hadde vært identisk med prosentandel døde blant dem med høyere universitetsutdanning.

\begin{tabular}{|c|c|c|c|c|}
\hline \multirow[b]{2}{*}{ Dødsårsaksgruppe } & \multicolumn{2}{|c|}{$\begin{array}{c}\text { Antall dødsfall } \\
\text { som ville vært } \\
\text { unngått }\end{array}$} & \multicolumn{2}{|c|}{$\begin{array}{l}\text { Fordeling (\%) av } \\
\text { dødsfallene som } \\
\text { ville vært unngått }\end{array}$} \\
\hline & Menn & Kvinner & Menn & Kvinner \\
\hline Alle årsaker & 28031 & 15101 & 100,0 & 100,0 \\
\hline Infeksjonssykdommer & 219 & 174 & 0,8 & 1,2 \\
\hline Magekreft & 434 & 129 & 1,5 & 0,9 \\
\hline Kreft i tykktarm, endetarm & 345 & -66 & 1,2 & $-0,4$ \\
\hline Lungekreft & 3503 & 1897 & 12,5 & 12,6 \\
\hline Brystkreft & & -204 & & $-1,4$ \\
\hline Annen kreft & 1836 & 2509 & 6,5 & 16,6 \\
\hline Alkoholbetingete psykoser mv & 913 & 185 & 3,3 & 1,2 \\
\hline Stoffavhengighet mv & 1061 & 231 & 3,8 & 1,5 \\
\hline Ischemisk hjertesykdom & 7180 & 2972 & 25,6 & 19,7 \\
\hline Karsykdommer i hjernen & 1267 & 1260 & 4,5 & 8,3 \\
\hline Andre sirkulasjonsorganer & 2307 & 998 & 8,2 & 6,6 \\
\hline Kronisk lungesykdom & 1644 & 1626 & 5,9 & 10,8 \\
\hline Annen åndedrettsykdom & 426 & 423 & 1,5 & 2,8 \\
\hline Leversykdommer & 683 & 400 & 2,4 & 2,6 \\
\hline Symptomer, ubestemt & 1209 & 354 & 4,3 & 2,3 \\
\hline Transportulykker & 605 & -93 & 2,2 & $-0,6$ \\
\hline Andre ulykker & 1080 & 151 & 3,9 & 1,0 \\
\hline Selvmord & 823 & -46 & 2,9 & $-0,3$ \\
\hline Andre dødsårsaker & 2496 & 2201 & 8,9 & 14,6 \\
\hline
\end{tabular}

kant for begge kjønn, men litt sterkere blant mennene enn blant kvinnene. Dette hovedmønsteret kunne gjenfinnes for de fleste enkelte dødsårsaksgruppene, men utdanningsforskjellene varierte mellom dem. Utdanningsgradienten var særskilt sterk for dødsårsaker knyttet til stoffavhengighet og alkoholmisbruk, men forholdsvis svak eller praktisk talt fraværende for en rekke krefttyper. Unntaket blant kreftformene er lungekreft, der utdanningsgradienten var noe sterkere enn gjennomsnittet blant menn og enda mer over gjennomsnittet blant kvinner. Også for kroniske lungesykdommer/KOLS var utdanningsforskjellene særskilt store blant kvinner og over gjennomsnittet blant menn.
Hovedresultatene i denne studien samsvarer tildels med studier fra andre "rike" land. En studie i åtte vesteuropeiske land viste for eksempel at blant middelaldrende var utdanningsforskjellene små for død av tykktarm/endetarmskreft, prostatakreft (menn) og brystkreft (kvinner) (10). I noen land var brystkreftdødeligheten omvendt relatert til kvinnenes utdanningsnivå, i motsetning til resultatene her der det ikke var utdanningsforskjeller for brystkreft. Analysen av de vest-europeiske utvalgene viste også særskilt sterke utdanningsforskjeller for kroniske lungelidelser og tildels også for lungekreft, og dessuten for ischemisk hjertesykdom blant kvinner. En australsk studie fra slutten av 1990-tallet har vist at dødeligheten av respirasjonssykdommer, lungekreft og trafikkulykker for menn var relatert til sosioøkonomiske forskjeller mellom bostedsområder. Tilsvarende var det en samvariasjon mellom sosioøkonomiske faktorer og bostedsområde for dødeligheten av lunge-, respirasjonssykdommer og ischemisk hjertesykdom blant kvinner. Dødeligheten av andre kreftsykdommer enn lungekreft var imidlertid lite relatert til sosioøkonomiske forskjeller mellom bostedsområdene (11).

Disse funnene kan være et utgangspunkt for å drøfte årsakene bak de sosiale helseulikhetene. De sterke utdanningsforskjellene i misbruksrelaterte dødsårsaker synes for eksempel enkle å forstå når det gjelder de nærliggende årsakene. Fraværet av utdanningsforskjeller for tykk/endetarmskreft kan peke i retning av at årsakskompleksene bak disse lidelsene er noenlunde jevnt fordelt i det sosioøkonomiske hierarkiet.

Det dominerende mønsteret er at dødeligheten for de aller fleste dødsårsaker stiger trinnvist med synkende utdanning. Dette har blant annet ført til hypoteser om at en generell sårbarhet ("general susceptibility") blant vanskeligstilte grupper ligger bak $(12,13)$. Slik generell sårbarhet med relevans for mange typer sykdommer og lidelser kunne for eksempel bestå i mer usunne oppvekstvilkår eller mindre ressurser for å håndtere psykososialt stress, jo lavere en er plassert $i$ utdanningshierarkiet. At utdanningsulikhetene varierer mellom dødsårsakene tyder imidlertid på at det også 
må være spesifikke forhold knyttet til de enkelte lidelsene.

Å drøfte årsaksspørsmålene videre går utover rammen for denne artikkelen. Disse analysene tar først og fremst sikte på å beskrive omfanget av helseulikhetene mellom utdanningsnivåene. Hvordan utdanning inngår $\mathrm{i}$ årsakskjedene er et komplisert spørsmål. Funnene i seg selv sier ikke noe om den spesifikke rollen utdanning spiller i de prosessene som frambringer helseulikhetene. Heller ikke er det uten videre gitt hvordan det samlete mønsteret av helseulikheter ville påvirkes av et økt utdanningsnivå.

Et viktig resultat er at det ikke er svært stort sammenfall mellom hvilke dødsårsaker som viser størst utdanningsvariasjon og hvilke som alt $i$ alt betyr mest for forskjellene i levealder og dødelighet mellom utdanningsgruppene. Utdanningsgradienten er sterkest for dødsfall relatert til typiske misbruksrelaterte lidelser (stoff, alkohol), men siden disse lidelsene utgjør en begrenset andel av dødsårsakene er ikke deres bidrag til de samlete utdanningsforskjellene like markert. De lavere utdanningsgruppers "overdødelighet" i hjerteog karsykdommer, lungekreft og kroniske lungelidel-
ser/KOLS utgjør et tungtveiende bidrag til den sosiale ulikheten i dødelighet, og dette mønsteret framtrer også i andre "rike" land $(10,11,14)$.

Dette innebærer at en reduksjon av utdanningsforskjellene når det gjelder disse lidelsene, og spesielt hjerte- og karsykdommer, vil ha særlige positive konsekvenser for omfanget av de sosioøkonomiske helseforskjellene.

\section{KONKLUSJON}

Utdanningsforskjellene i Norge i dødelighet blant voksne er betydelige og utgjør et stort folkehelseproblem. Utdanningsforskjellene er mest markante for typiske misbruksrelaterte dødsårsaker. Bidraget til utdanningsforskjellene i generell dødelighet er likevel størst fra hjerte- og karlidelser og dernest fra lungekreft og kroniske lungesykdommer. Samlet står disse lidelsene for omlag $60 \%$ av de "ekstra" dødsfallene en kan si er forbundet med utdanningsforskjellene. Funnene er relevante for diskusjonen om strategier for å motvirke de sosioøkonomiske helseulikhetene.

\section{REFERANSER}

1. DH. Tackling health inequalities. A programme for action. London: Department of Health, 2003.

2. Stronks K, Mackenbach JP. Evaluating the effect of policies and interventions to address inequalities in health: lessons from a Dutch programme. Eur J Public Health 2006; 16: 346-53.

3. SHDir. Gradientutfordringen. Sosial-og helsedirektoratets handlingsplan mot sosiale ulikheter i helse. Oslo: Sosial- og helsedirektoratet, 2005.

4. Mackenbach JP, Bakker M, red. Reducing inequities in health. A European perspective. London: Routledge, 2002.

5. HOD. Nasjonal strategi for å utjevne sosiale helseforskjeller. St.meld. nr. 20 (2006-2007). Oslo: Helse- og omsorgsdepartementet, 2007.

6. Akselsen A, Dahl G, Lajord J, Sivertstøl Ø. FD-Trygd. Variabelliste. Notater 2000/70. Oslo: Statistisk sentralbyrå, 2000.

7. SSB. Dødsårsaker 1991-2000. Norges offisielle statistikk D 189. Oslo - Kongsvinger: Statistisk sentralbyrå, 2003.

8. Næss Ø, Rognerud M, Strand BH. Sosial ulikhet i helse. En faktarapport. Rapport 2007:1. Oslo: Folkehelseinstituttet, 2007.

9. Zahl P-H, Rognerud M, Strand BH, Tverdal A. Bedre helse - større forskjeller. Rapport 2003:1. Oslo: Folkehelseinstituttet, 2003.

10. Huisman M, Kunst AE, Bopp M, Borgan BK, Borrell C, Costa G, et al. Educational inequalities in causespecific mortality in middle-aged and older men and women in eight western European populations. Lancet 2005; 365: 493-500.

11. Turrell G, Mathers C. Socioeconomic inequalities in all-cause and specific-cause mortality in Australia: 1985 1987 and 1995-1997. Int J Epidemiol 2001; 30: 231-9.

12. Syme SL, Berkman LF. Social class, susceptibility and sickness. Am J Epidemiol 1976; 104: 1-8.

13. Najman JM. Commentary: General or cause-specific factors in explanations of class inequalities in health. Int J Epidemiol 2001; 30: 296-7.

14. Middelkoop BJC, Struben HWA, Burger I, Vroom-Jongerden JM. Urban cause-specific socioeconomic mortality differences. Which causes of death contribute most? Int J Epidemiol 2001; 30: 240-7. 